\title{
Comparison of ultrasonic and photographic methods of axial length measurements of the eye
}

\author{
R. H. B. GREY, E. S. PERKINS AND MARIE RESTORI
}

SUMMARY The axial length of 25 eyes was measured by the photographic method and by ultrasonography. The photographic measurements were consistently larger than the ultrasonic, but analysis gave a correlation coefficient of $r=0 \cdot 8483$. The results suggest that the centre of rotation of the eye lies posterior to the anatomical centre of the globe. Using an empirical method of calculation and allowing for an error of $\pm 0.3 \mathrm{~mm}$ in the ultrasonic measurement, the photographic results were within $\pm 0.5 \mathrm{~mm}$ in 13 eyes and $\pm 1.0 \mathrm{~mm}$ in 7 eyes.

The photographic method may be helpful as a guide to the power of intraocular lens implants and for comparing axial lengths in population studies.

Recently Perkins et al. (1976) described a photographic method of measuring the axial length of the eye. Although this technique has clear advantages over the pre-existing methods in terms of simplicity and expense of equipment and its ease of application to children, the accuracy of the results in absolute terms was open to doubt. There was a high degree of correlation between the axial length measurements and the degree of ametropia, but there appeared to be an overestimate of approximately $3 \mathrm{~mm}$ when compared to the estimates of axial length by previous methods.

In the present study axial length measurements were taken by both photographic and ultrasonic techniques on the same eyes and the results compared.

\section{Subjects and methods}

25 eyes in 22 subjects were examined. 19 patients (21 eyes) were referred to the Ultrasound Department of Moorfields Eye Hospital for a routine ultrasonography, and 3 subjects (4 eyes) were volunteer members of the staff of Moorfields Eye Hospital. All had axial length measurements taken by ultrasound A-scan and before or immediately after this they had axial length photographs taken. For these latter measurements to be taken all the patients were required to have sufficient visual acuity to be able to fixate on the small central fixation spot which appears in the centre of the camera lens.

\section{PHOTOGRAPHIC METHOD}

The photographic equipment used was similar to

Address for reprints: Professor E. S. Perkins, Institute of Ophthalmology, Judd Street, London WC1H 9QS. that described by Perkins with a reflex camera mounted between 2 slit flashes $\left(37^{\circ} 28^{\prime}\right.$ apart) on an arc centred on the focal point of the camera lens.

\section{Calibrations}

Before the study was undertaken the camera equipment was calibrated. Using various steel balls of known diameter mounted eccentrically by a precisely known amount and movable through an arc of $37^{\circ}$ it was possible to mimic different sized human eyes and photograph them in a manner similar to that used in the subsequent study.

In the primary position the image separation on the film is directly proportional to the radius of curvature of the steel ball or cornea. Thus it was possible to arrive at a factor which allowed direct calculation of the radius of the corneal curvature from the film negative:

$$
\mathrm{r}=2 \times \mathrm{f}=\mathrm{n} \times 0.332
$$

$$
\begin{aligned}
\text { where } \mathrm{r} & =\text { radius of curvature }(\mathrm{mm}) \\
\mathrm{f} & =\text { focal length for point source } \\
\mathrm{n} & =\text { number of scale divisions between the film } \\
& \text { images in primary position. }
\end{aligned}
$$

The distance from the focal point of the cornea to the centre of rotation of the eye can be calculated by allowing for camera magnification $(\times 1 \cdot 88)$, scale differences on the negative $(\times 5)$, and the angle of deviation from the primary position $\left(18^{\circ} 44^{\prime}\right)$, thus:

$$
\begin{aligned}
\mathrm{y} & =\frac{\mathrm{n}}{1.88 \times 5 \times 2} \text { sine } 18^{\circ} 44^{\prime}=\frac{\mathrm{n}^{\prime}}{6.04} \\
\text { where } \mathrm{y}= & \begin{array}{l}
\text { distance from focal point of cornea to centre } \\
\text { of rotation }(\mathrm{mm})
\end{array} \\
\mathrm{n}^{\prime} & =\begin{array}{l}
\text { number of scale divisions between the film } \\
\text { images in deviated positions }\left(37^{\circ} 28^{\prime}\right) .
\end{array}
\end{aligned}
$$

The theoretical length of the eye can then be 
found, namely, $1=2 y+2 f$ or $2 y+r$, where $1=$ axial length $(\mathrm{mm})$.

\section{Clinical measurements}

The technique of photography used clinically was exactly as described by Perkins, and each patient had 2 keratometry photographs in the primary position and 3 'deviated' photographs looking at each flash in turn.

\section{A-SCAN METHOD}

A $10-\mathrm{MHz}$ focused transducer was coupled to the eye by means of a bath containing Ringer's solution at $37^{\circ} \mathrm{C}$. Eye movements were reduced to a minimum with the aid of a fixation light for the eye not under examination. The approximate position of the optical axis was located using the mechanical linear B-scan facility on the Moorfields system, and the transducer position then adjusted to attain maximum echoes from the anterior and posterior lens surfaces. Ocular distances along the optic axis were measured in microseconds and converted to millimetres using the following assumed velocity of sound propagation in ocular tissues at $37^{\circ} \mathrm{C}$ :

aqueous humour $1500 \mathrm{~m}$ per second (Begui, 1954) lens material $1620 \mathrm{~m}$ per second (Begui, 1954)

vitreous humour $1520 \mathrm{~m}$ per second (Begui, 1954). In those eyes with an irregular-shaped posterior segment (indicated on the B-scan) the length of the vitreous was taken as the maximum vitreous length along a horizontal axis.

The axial length measurements using this method are accurate to $\pm 0.3 \mathrm{~mm}$.

\section{Results}

From the calibration tests it was found that the accuracy of the 'keratometry' readings on the steel balls ranged from +0.01 to $+0.22 \mathrm{~mm}$ (mean $+0.09 \mathrm{~mm})$ and the accuracy of the 'total length' measurements ranged from +0.65 to $+0.37 \mathrm{~mm}$ (mean $+0.48 \mathrm{~mm}$ ). Thus the theoretical accuracy of the photographic method was within $0.5 \mathrm{~mm}$.

The clinical measurements are summarised in Fig. 1 and Table 1. As the ultrasound A-scan measures from the anterior corneal surface to the anterior retinal surface, $1.4 \mathrm{~mm}$ has been added to the A-scan length in Table 1 . This allows $1.15 \mathrm{~mm}$ for the scleral thickness and $0.25 \mathrm{~mm}$ for the choroidal thickness, which according to Duke-Elder and Wybar (1961a) is the average thickness of these structures.

It will be seen from the graph and the figures that the axial length as measured by the photographic method is consistently greater than that obtained by ultrasonography even when allowance is made

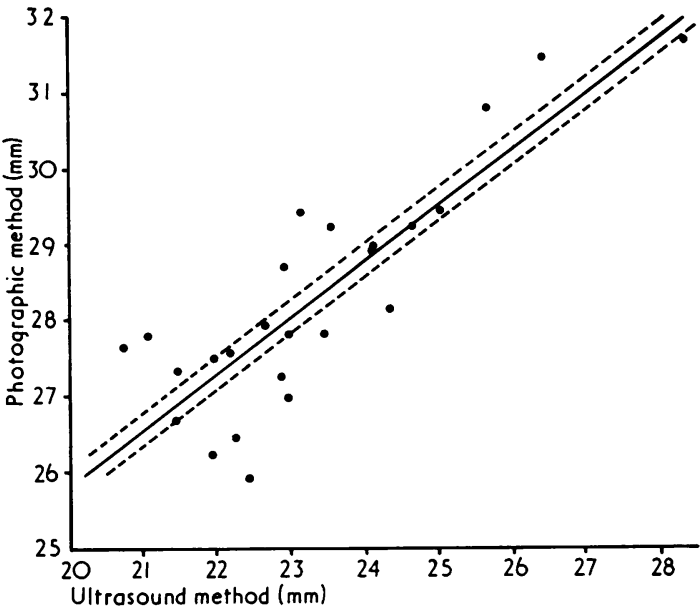

Fig. 1 Axial lengths (abscissa) using the photographic method were derived from the theoretical calculation $l=2 y+r$ where $l$ is the axial length, $y$ is the distance from the focal point of the cornea to the centre of rotation and $r$ is the radius of curvature of the cornea. Ultrasonic measurements are plotted along the coordinate. The dotted lines represent the possible error of the ultrasonic measurement: $\pm 0.3 \mathrm{~mm}$

Table 1

\begin{tabular}{|c|c|c|c|}
\hline $\begin{array}{l}\text { A-scan } \\
+1.4 \mathrm{~mm}\end{array}$ & $\begin{array}{l}\text { Radius of } \\
\text { curvature (r) }\end{array}$ & $\begin{array}{l}\text { Distance from } \\
\text { corneal image } \\
\text { to centre of } \\
\text { rotation }(y)\end{array}$ & $\begin{array}{l}\text { Axial length } \\
(2 y+r)\end{array}$ \\
\hline $\begin{array}{l}22 \cdot 12 \\
22 \cdot 47 \\
22 \cdot 85 \\
22 \cdot 87 \\
23 \cdot 32 \\
23 \cdot 35 \\
23 \cdot 59 \\
23 \cdot 63 \\
23 \cdot 81 \\
24 \cdot 04 \\
24 \cdot 27 \\
24 \cdot 31 \\
24 \cdot 37 \\
24 \cdot 37 \\
24 \cdot 53 \\
24 \cdot 83 \\
24 \cdot 93 \\
25 \cdot 50 \\
25 \cdot 52 \\
25 \cdot 73 \\
26 \cdot 05 \\
26 \cdot 42 \\
27 \cdot 04 \\
27 \cdot 80 \\
29 \cdot 70\end{array}$ & $\begin{array}{l}7 \cdot 80 \\
7 \cdot 96 \\
8 \cdot 04 \\
8 \cdot 10 \\
8 \cdot 00 \\
\mathbf{7} \cdot 64 \\
\mathbf{7} \cdot 80 \\
\mathbf{7} \cdot 48 \\
\mathbf{7} \cdot 80 \\
\mathbf{7} \cdot 64 \\
\mathbf{7} \cdot 88 \\
\mathbf{8} \cdot 58 \\
\mathbf{7} \cdot 60 \\
\mathbf{7} \cdot 64 \\
8 \cdot 30 \\
\mathbf{7} \cdot 96 \\
\mathbf{7} \cdot 88 \\
\mathbf{8} \cdot 14 \\
\mathbf{8} \cdot 50 \\
\mathbf{7} \cdot 96 \\
\mathbf{7} \cdot 94 \\
\mathbf{7} \cdot 92 \\
\mathbf{8} \cdot 30 \\
\mathbf{8} \cdot 30 \\
\mathbf{7} \cdot 60\end{array}$ & $\begin{array}{r}9.93 \\
9.93 \\
9.33 \\
9.62 \\
9.11 \\
9.93 \\
9.89 \\
9.49 \\
9.06 \\
10 \cdot 15 \\
9.69 \\
10.05 \\
9.69 \\
9.27 \\
10.57 \\
9.93 \\
10.68 \\
10.39 \\
10.24 \\
10 \cdot 10 \\
10.65 \\
10.76 \\
11.26 \\
11.59 \\
12.04\end{array}$ & $\begin{array}{l}27 \cdot 66 \\
27 \cdot 82 \\
26 \cdot 70 \\
27 \cdot 34 \\
26 \cdot 22 \\
27 \cdot 50 \\
27 \cdot 58 \\
26 \cdot 46 \\
25 \cdot 92 \\
27 \cdot 94 \\
27 \cdot 26 \\
28 \cdot 70 \\
26 \cdot 98 \\
26 \cdot 18 \\
29 \cdot 44 \\
27 \cdot 82 \\
29 \cdot 58 \\
28 \cdot 92 \\
28 \cdot 98 \\
28 \cdot 16 \\
29 \cdot 24 \\
29 \cdot 44 \\
30 \cdot 82 \\
31 \cdot 48 \\
31 \cdot 68\end{array}$ \\
\hline
\end{tabular}

for the thickness of the sclera. The difference varied from 1.81 to $5.35 \mathrm{~mm}$ (mean $3.54 \mathrm{~mm}$ ). There is, however, a good correlation between the results from the 2 methods $(r=0.8483)$ and the regression equation is $y=0.735 x+11 \cdot 15$, where $y$ is the 
photographic measurement and $\mathrm{x}$ the ultrasound. If this equation is applied to the data, the difference between the 2 methods is less than $\pm 0.5 \mathrm{~mm}$ in 10 eyes, between \pm 0.5 and \pm 1.0 in 8 , between \pm 1 and $\pm 1.5 \mathrm{~mm}$ in 6 , and only exceeds this value $(-1.7 \mathrm{~mm})$ in 1 eye.

Fig. 1 shows the regression line and the dotted lines indicate lines corresponding to $\pm 0.3 \mathrm{~mm}$ for the ultrasound method.

\section{Discussion}

In the photographic method what is actually measured is the radius of rotation of the corneal reflex about the centre of rotation of the posterior scleral segment (mean $10.5 \mathrm{~mm}$ ). The calculation assumed that the apex of the cornea lies on the circumference of the arc of the circle described by the posterior sclera (Duke-Elder and Wybar, 1961b) and that the centre of rotation of the globe is midway between the apex of the cornea and the posterior pole. The present results suggest that this assumption is not correct and that the distance from the apex of the cornea to the centre of rotation is greater than that from the latter to the posterior pole by approximately $3.5 \mathrm{~mm}$ (see Fig. 2). As anatomical measurements all agree that the eye is

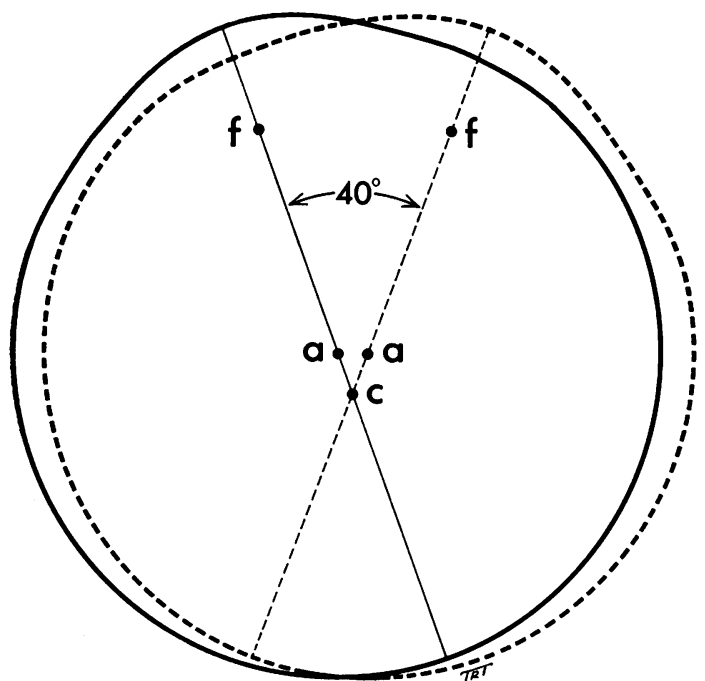

Fig 2. c represents the centre of rotation of the globe, a the anatomical centre (i.e., a point midway between the apex of the cornea and the posterior pole), and $f$ the focal point of the cornea. The distance of is approximately equal to the distance from $\mathrm{c}$ to the posterior pole of the eye so that the axial length equals $2 \mathrm{cf}$ and half the radius of curvature of the cornea

$f=$ focal point of cornea; $a=$ anatomical centre; $c=$ centre of rotation.
Table 2

\begin{tabular}{|c|c|c|c|}
\hline $\begin{array}{l}\text { A-scan } \\
+1.4 \mathrm{~mm}\end{array}$ & $2 y+f$ & Difference & $\begin{array}{l}\text { Difference } \\
\pm 0.3 \mathrm{~A} \text {-scan }\end{array}$ \\
\hline $\begin{array}{l}22 \cdot 15 \\
22 \cdot 47 \\
22 \cdot 85 \\
22 \cdot 87 \\
23 \cdot 32 \\
23 \cdot 35 \\
23 \cdot 59 \\
23 \cdot 63 \\
23 \cdot 81 \\
24 \cdot 04 \\
24 \cdot 27 \\
24 \cdot 31 \\
24 \cdot 37 \\
24 \cdot 37 \\
24 \cdot 53 \\
24 \cdot 83 \\
24 \cdot 93 \\
25 \cdot 50 \\
25 \cdot 52 \\
25 \cdot 73 \\
26 \cdot 05 \\
26 \cdot 42 \\
27 \cdot 04 \\
27 \cdot 80 \\
29 \cdot 70\end{array}$ & $\begin{array}{l}23 \cdot 77 \\
23 \cdot 68 \\
22 \cdot 68 \\
23 \cdot 29 \\
22 \cdot 21 \\
23 \cdot 69 \\
23 \cdot 68 \\
22 \cdot 72 \\
22 \cdot 28 \\
24 \cdot 13 \\
23 \cdot 32 \\
24 \cdot 41 \\
23 \cdot 17 \\
22 \cdot 36 \\
25 \cdot 29 \\
23 \cdot 85 \\
25 \cdot 30 \\
24 \cdot 85 \\
24 \cdot 72 \\
24 \cdot 18 \\
25 \cdot 27 \\
25 \cdot 48 \\
26 \cdot 67 \\
27 \cdot 33 \\
27 \cdot 89\end{array}$ & $\begin{array}{l}+1.65 \\
+1.21 \\
-0.17 \\
+0.42 \\
-1.11 \\
+0.34 \\
+0.09 \\
-0.91 \\
-1.53 \\
+0.09 \\
-0.95 \\
+0.10 \\
-1.20 \\
-2.01 \\
+0.76 \\
-0.98 \\
+0.37 \\
-0.65 \\
-0.80 \\
-1.55 \\
-0.78 \\
-0.94 \\
-0.37 \\
-0.47 \\
-1.81\end{array}$ & $\begin{array}{l}+1 \cdot 35 \\
+0.91 \\
\text { Within } \pm 0.3 \\
+0.12 \\
-0.81 \\
+0.04 \\
\text { Within } \pm 0.3 \\
-0.61 \\
-1.23 \\
\text { Within } \pm 0.3 \\
-0.65 \\
\text { Within } \pm 0.3 \\
-0.90 \\
-1 \cdot 71 \\
+0.46 \\
-0.68 \\
+0.07 \\
-0.35 \\
-0.50 \\
-1.35 \\
-0.48 \\
-0.64 \\
-0.07 \\
-0.17 \\
-1.51\end{array}$ \\
\hline
\end{tabular}

almost spherical, it would seem that the globe does not rotate about its anatomical centre but about a point more posterior. The focal point of the cornea (radius of curvature $\div 2$ ) is situated very close to $3.5 \mathrm{~mm}$ from the apex of the cornea, and it was found empirically that a much closer correspondence between the ultrasonic and photographic methods could be obtained by calculating the axial length from the photographs by using the formula $1=2 y$ $+f$, where $y$ is the distance from the position of the corneal reflex to the centre of rotation and $f$ is the corneal radius $\div 2$.

Table 2 shows that in 17 of the 25 eyes the 2 measurements were within $1.0 \mathrm{~mm}$, and in 9 eyes the results were within $0.5 \mathrm{~mm}$. In 8 eyes the error was greater than $1.0 \mathrm{~mm}$, and in 1 eye it was greater than $2.0 \mathrm{~mm}$. If the limits of accuracy of the ultrasonography are taken into account the errors are as follows:

\begin{tabular}{ll} 
No. of eyes & Error \\
\hline 4 & no difference \\
9 & within $\pm 0.5 \mathrm{~mm}$ \\
7 & within $\pm 1.0 \mathrm{~mm}$ \\
5 & over $\pm 1.0 \mathrm{~mm}$
\end{tabular}

This empirical method of calculation is simpler than using a conversion table or graph based on the plotted values in Fig. 1, and although it may have no theoretical justification it does give results which agree with previous work.

Park and Park (1933) measured the centre of rotation in 14 subjects over a horizontal arc of movement from $38^{\circ}$ temporally to $39^{\circ}$ nasally. They found that the centre lay on the nasal side of the 
visual axis and moved on average from 12.95 to $14.73 \mathrm{~mm}$ behind the corneal apex. In the primary position it lay $13.84 \mathrm{~mm}$ behind the cornea. If, therefore, the corneal apex lay on the scleral circle, this would give an average axial length of $27.68 \mathrm{~mm}$ in these 14 subjects. Their refraction and axial lengths were not recorded, but it would seem likely that their subjects were emmetropic and it can be concluded either that the cornea protrudes in front of the scleral circle or the centre of rotation does not lie equidistant from the apex of the cornea and the posterior pole of the eye.

Given a centre of rotation of $13.84 \mathrm{~mm}$ behind the cornea and a corneal radius of $7.8 \mathrm{~mm}$ the average distance from the focal point of the cornea to the centre of rotation $(y)$ would be $9.98 \mathrm{~mm}$. Thus $2 y+r$ would be $27.76 \mathrm{~mm}$, i.e., about $3 \mathrm{~mm}$ too long, and $2 y+f$ would be $23.86 \mathrm{~mm}$, which is close to the average length of $24.15 \mathrm{~mm}$ quoted by Duke-Elder and Wybar (1961c).

During the course of this study 1 patient with nanophthalmos was measured by both techniques; she was not included in the results. She had a refraction of 18 dioptres of hypermetropia and an axial length by ultrasonography of $15.65 \mathrm{~mm}$ (right) and $14.79 \mathrm{~mm}$ (left). The photographic method gave lengths of $17.86 \mathrm{~mm}$ and $17.84 \mathrm{~mm}$. It would seem that for a grossly short eye the photographic method becomes inaccurate perhaps because the posterior segment is aspherical and the sclera thicker.

The photographic technique measures axial length along the visual axis, and the ultrasonic technique used (for regular-shaped eyes) measures axial length along the optic axis. Jansson (1963) has shown that the difference in axial lengths along these axes is $0 \cdot 1 \mathrm{~mm}$. Several workers have described ultrasonic systems for axial length measurements along the visual axis. Giglio (1969) and Coleman (1969) have described systems operating at $20 \mathrm{MHz}$ and said to be capable of accuracies in axial length measurements to within less than 0.05 and $0.03 \mathrm{~mm}$, respectively.

Accommodation of eyes during the ultrasonic and photographic procedures may also account for differences in axial length measurements as measured by these 2 techniques.

The photographic technique is not accurate enough to be a refraction tool under normal circumstances, but it may have possibilities as a guide to the power of intraocular implants in cataract surgery. The photograph in the primary position gives an accurate keratometry reading, and thus a preoperative measure of corneal refractive power, although this may change postoperatively.

Using the empirical method of calculating the axial length would allow an estimate of the required refractive power of an implant lens to within 1.5 dioptres in $36 \%$ of cases and within 3 dioptres in $68 \%$ of cases.

One object of attempting to develop a simple method of measuring axial length was for use in population surveys, particularly with a view to the investigation of myopia, where ultrasonography techniques would be impractical. There are both theoretical and practical sources of error in the photographic method, and the ultrasonic method is clearly more accurate for an individual eye. However, it seems likely that for comparing axial lengths between emmetropes and myopes in a population any significant differences in axial length would be detectable by the photographic method. Its ease of application is particularly valuable for children, and as the error in any given eye will probably remain constant changes in axial length, e.g., with growth or the development of myopia, should be reliably measured. As the technique also provides a measurement of the radius of curvature of the cornea, the results would enable differentiation between ametropia due to radius of curvature of the cornea, axial length, or refractive power of the lens.

A cause of inaccuracy in the photographic method other than anatomical abnormality could be translatory movements on rotation of the eye. By taking the measurements in the horizontal plane the translatory movements due to the oblique muscles are minimal, but some lateral movement may occur. Head movements during photography have a similar effect, and this is definitely a major source of error. The 2 criteria for good photographic results are that the patient is able to see the fixation lights and that the head is held still during the time when the camera shutter is held open.

Inaccurate focusing of the images of the corneal reflex are another source of error, and it may be possible to devise optical methods for measuring the separation of the images without the necessity for photography. Experiments along these lines are in progress.

We should like to thank the Computer Department at the Institute of Ophthalmology for help with the statistical analyses and Mr Tarrant of the Department of Audio-Visual Communications for the diagram.

\section{References}

Begui, Z. E. (1954). Acoustic properties of the refractive media of the eye. Journal of the Acoustic Society of America, 26, 365-368.

Coleman, D. J. (1969). Ophthalmic biometry using ultrasound. International Ophthalmology Clinics, 9, 667-683.

Duke-Elder, S., and Wybar, K. C. (1961a). System of Ophthalmology, Vol. 2, Ch. III, pp. 131-146. Kimpton: London. 
Duke-Elder, S., and Wybar, K. C. (1961b). System of Ophthalmology, Vol. 2, Ch. III, pp. 78-80. Kimpton: London.

Duke-Elder, S., and Wybar, K. C. (1961c). System of Ophthalmology, Vol. 2, Ch. III, pp. 80-82. Kimpton: London.

Giglio, E. J. (1969). Ultrasonic system for measurement of intraocular distances in Gitter, K. A., et al. (eds.) Ophthalmic Ultrasound, Proceedings of the Fourth International Congress of Ultrasonography in Ophthalmology, Philadelphia, Pennsylvania, pp. 122-133. Mosby: St Louis.
Jansson, F. (1963). Measurement of intraocular distances by ultrasound. Acta Ophthalmologica, supplement 74, p. 51.

Park, R. S., and Park, G. E. (1933). Center of ocular rotation in horizontal plane. American Journal of Physiology, 104, 545-552.

Perkins, E. S., Hammond, B., and Millikin, A. B. (1976). Simple method of determining the axial length of the eye. British Journal of Ophthalmology, 60, 266-270. 